\title{
The Tensile Strength of Loess in Northwest China by Unconfined Penetration Test and the Distinct Element Simulation
}

\author{
Xuyang Wu $\mathbb{D}^{1},{ }^{1}$ Yun Bao $\mathbb{D}^{\circ},{ }^{2}$ Mingyang Ren, ${ }^{1}$ and Qingguo Liang ${ }^{3}$ \\ ${ }^{1}$ School of Civil and Transportation Engineering, Henan University of Urban Construction, Pingdingshan 467036, Henan, China \\ ${ }^{2}$ School of Materials and Chemical Engineering, Henan University of Urban Construction, Pingdingshan 467036, Henan, China \\ ${ }^{3}$ School of Civil Engineering, Lanzhou Jiaotong University, Lanzhou 730070, Gansu, China
}

Correspondence should be addressed to Yun Bao; 20181020@hncj.edu.cn

Received 9 April 2021; Revised 30 May 2021; Accepted 11 June 2021; Published 29 June 2021

Academic Editor: Peng Zhang

Copyright ( $\odot 2021$ Xuyang Wu et al. This is an open access article distributed under the Creative Commons Attribution License, which permits unrestricted use, distribution, and reproduction in any medium, provided the original work is properly cited.

The unconfined penetration test (UP test) is one of the indirect methods to measure the tensile strength of soils. Through a series of UP tests of undisturbed and remolded loess, the split angle $(\alpha)$ of the wedge body which was shaped in the process of the experiment was discussed. And then, the particle movement, the force transfer, and the fracture development law of the sample were studied by the distinct element method $\left(\mathrm{PFC}^{2 \mathrm{D}}\right)$. The experiment and numerical simulation results show the following: (1) the split angle $(\alpha)$ presents an exponential decrease with tensile strength $\left(\sigma_{t}\right)$ and a linear decrease with internal friction angle $(\varphi)$; (2) $K$ that can be written as $\tan (2 \alpha+\varphi)$ is a coefficient to calculate tensile strength, which is equal to 2.00 for remolded loess and 1.50 for undisturbed loess; (3) the distinct element simulation shows that the resisting force by the UP test comes from both tensile stress and shear stress; (4) the tensile fractures and shear fractures appear at almost the same time when the tensile stress is approximately $70 \%$ of tensile strength.

\section{Introduction}

Loess is widely distributed in the world, accounting for $10 \%$ of the world's land area. China loess is the most widely distributed (the area is about 630,000 square kilometers) and thickest (the thickness is generally $50 \mathrm{~m}-200 \mathrm{~m}$ and the thickest is 336 meters in Lanzhou, Gansu province) in the world. The loess in China is mainly distributed in the loess plateau, accounting for $72.4 \%$ of China's loess area. The tensile strength of loess is one of the mechanical parameters that are very small and always ignored by engineering designers. However, there are many disasters related to tensile strength, such as ground fissures [1] and the cracks in Earth and rockfill dam [2]; some others may be destroyed by the tensile-shear coupling actions, for example, loess slope instability [3]. On the aspect of tensile strength measuring method, the UP test as an indirect method is accepted by researchers major depending on two advantages: (1) the failure position happens in the weakest plan of test samples, and the result is more helpful for determining the real tensile strength of soils; (2) the apparatus is simple, easy for sampling, and easy to operate. Moreover, the tensile strength measured by the UP test has a very high correlation with some other methods, such as the bend beam method or the direct split tensile test [4], which confirmed that the UP test can be used to determine the tensile strength of geomaterials; in addition, that study also points out that when the heightdiameter ratio of sample is close to 1 , the value of coefficient $K$ which is determined by the split angle $(\alpha)$ and the internal friction angle $(\varphi)$ in the tensile strength formula is always set as 1 . It is worth noting that the value of $K$ is recommended based on a lot of clay specimens collected from different places in the USA. And then, the factors influencing the UP test, including loading rate, the radius of loading disk, and specimen size, were also studied [5]. For loess, it is a special soil with structure strength $[6,7]$ and water sensitiveness [8], which decide the special performance in strength and deformation that may lead to the value of $\mathrm{K}$ which is different [9]. On the aspect of tensile strength, [10] collected the test results of Malan loess's tension characteristics in China, 
pointing out that tensile strengths have a strong correlation with water content and dry density, and the tensile strength of Malan loess in China ranges from $10 \mathrm{kPa}$ to $160 \mathrm{kPa}$; [11] collected the Q2 undisturbed loess samples from Yanan city and Lanzhou city in China to test the tensile strength by UP test; the results show that the tensile strength of Q2 undisturbed loess in China ranges from $67.73 \mathrm{kPa}$ to $282.55 \mathrm{kPa}$. On the aspect of numerical modeling, the discrete element method can be used to simulate the discontinuous material, and it is widely used to simulate the fracture characteristics of rock [12, 13], sandy soil [14], or coarse soil [15]. Loess belongs to floury soil if it is classified by particle size, so discrete element simulation is rarely used to study the fracture characteristics of loess before. However, loess also has obvious discreteness and porous medium characteristics, so structure property exists, and the samples show obvious brittle failure characteristics by the UP test [9]. Therefore, the discrete element method is also trying to use to study the microfracture process analysis in recent years $[16,17]$.

Although there are abundant research studies on the tensile strength of loess, there is uncertainty that the recommended value of $K$ obtained by clay tests suits loess, and the relation between mechanical parameters is unclear for remolded loess and undisturbed loess. In addition, the microcosmic failure process of the loess sample by the UP test also lacks study, such as on the aspect of displacement evolution rule, force evolution rule, and the fractures evolution rule. Therefore, based on a series of UP tests, triaxial shear tests, and unconfined compressive strength tests of loess, the diversity of split angle $(\alpha)$, coefficient $K$, and the relation between tensile strength and other mechanical parameters were discussed. Based on the particle flow theory, the rules of fracture evolution, microparticles displacement evolution, and force evolution were studied by the discrete element method $\left(\mathrm{PFC}^{2 \mathrm{D}}\right)$.

\section{Experimental Material and Test Method}

2.1. The Sample Location and the Physical Property. The undisturbed loess is taken from the excavation face of tunnels under construction, which belong to the BaojiLanzhou high-speed railway and Baotou-Xian railway. The sampling process in one of the tunnels (Xujiachuan tunnel) is shown in Figure 1. In addition, some remolded loess is taken from the foot of an artificial slope in Lanzhou. The geographic positions of samples are marked in Figure 2. The detailed information of loess locations is listed in Table 1. The range of optimum moisture content is from $15.5 \%$ to $16.5 \%$, and the range of maximum dry density is from $1.68 \mathrm{~g} /$ $\mathrm{cm}^{3}$ to $1.73 \mathrm{~g} / \mathrm{cm}^{3}$. Moreover, the physical property of testing samples is listed in Table 2.

2.2. Experimental Program. The unconsolidated-undrained triaxial shear test and unconfined compressive strength test were conducted in a conventional strain-controlled triaxial instrument. The tensile strength test was conducted by the triaxial instrument which is improved (Figure 3(a)). The size of samples used to test the shear strength and the unconfined compressive strength is controlled with a height of $125 \mathrm{~mm}$ and a diameter of $61.8 \mathrm{~mm}$; the load rate is $1.25 \mathrm{~mm} / \mathrm{min}$. The size of samples used to test the tensile strength is controlled with a height of $62.5 \mathrm{~mm}$ and a diameter of $61.8 \mathrm{~mm}$; the load rate is $1.00 \mathrm{~mm} / \mathrm{min}$. The loading column is a rigid cylinder with a diameter of $15.45 \mathrm{~mm}$ and a height of $20.00 \mathrm{~mm}$. The static pressing method was used for remolded loess, and the artificial cut method was used for undisturbed loess.

The mechanical mechanism process of the UP test can be simply expressed as follows (Figure 3(b)):

(1) The two rigid columns are, respectively, laid on the top and bottom central surface of the sample, moving to each other along the central line with a very small relative velocity

(2) The density of the soil under rigid column will increase with a relative displacement appeared among the soil particles

(3) Then, two cones of soil with high density will be formed on the top and bottom and moves to each other along with the two rigid columns; thus, the tensile stress which is perpendicular to the center axial line of the rigid columns will be generated

From the perspective of energy, the downward force acted on the disks does work on the soil; when the instantaneous power of the axial force is equal to or larger than the dissipation power in the soil specimen, the soil specimen will be broken in the tension pattern. The dissipation power in the soil specimen is due to two parts: the first part is from the power where the cone plane spreads outward with the relative velocity to resist the shear stress; the second part is the power where any point along the vertical cracking moves horizontally with the relative velocity to resist the tensile stress, which can be used to indirectly calculate the tensile strength of soil specimen. The above mechanisms involved in the unconfined penetration test indicate that both the shear strength and the tensile strength contribute to the entire bearing capability of the soil specimen and that some inherent relationships exist between them.

The formula of calculating tensile strength in geomaterial by the UP method can be written as follows, as proposed by [4]:

$$
\sigma_{t}=\frac{P_{\max }}{\pi\left(K R H-r^{2}\right)},
$$

where

$$
K=\tan (2 \alpha+\varphi)
$$

where $P_{\max }$ is the maximum of axial force $(\mathrm{N}), R$ is the radius of the soil sample $(\mathrm{cm}), r$ is the radius of the loading disk $(\mathrm{cm}), H$ is the height of the soil sample $(\mathrm{cm}), \alpha$ is the split angle of cone body $\left({ }^{\circ}\right)$, and $\varphi$ is the internal friction angle $\left({ }^{\circ}\right)$. The value of $K$ is a very important parameter to calculate the tensile strength and set it as 1 . 


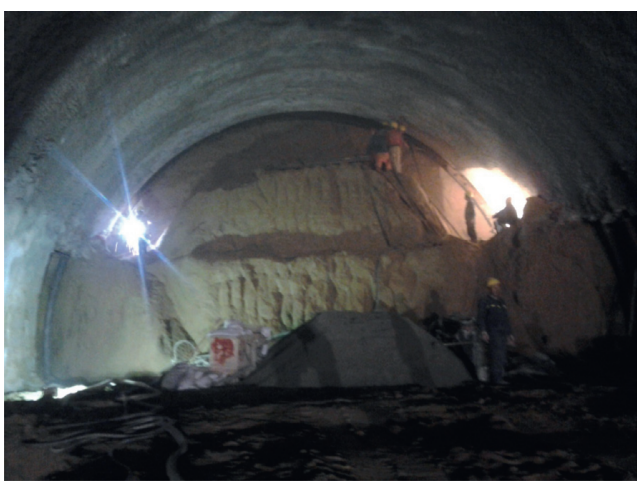

(a)

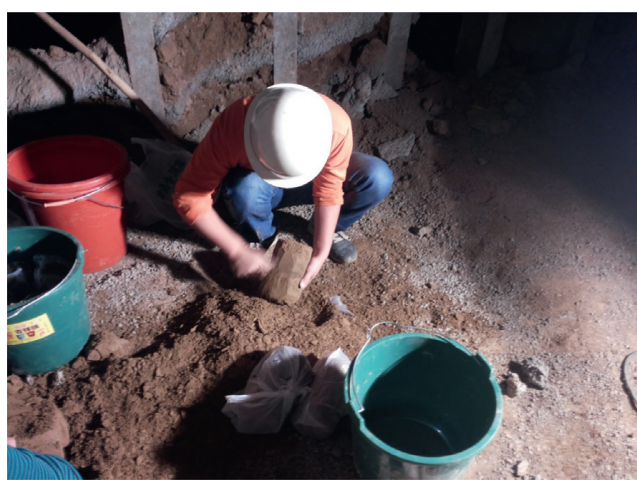

(c)

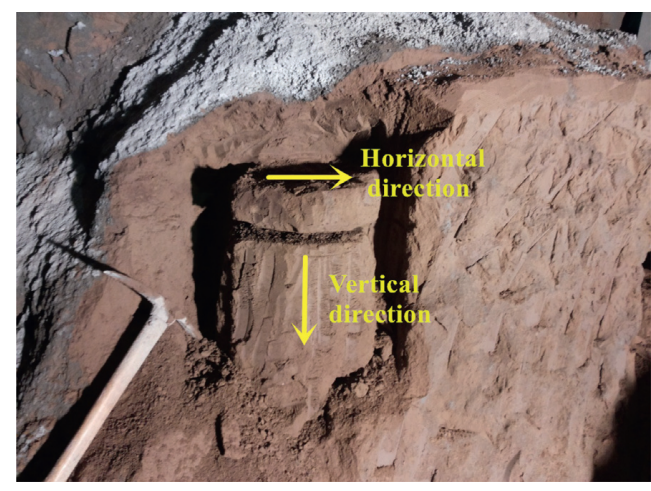

(b)

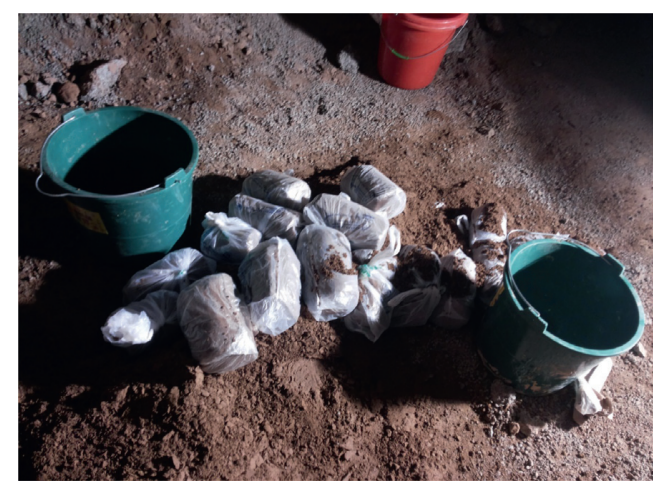

(d)

Figure 1: The sampling process. (a) The excavation face of Xujiachuan tunnel. (b) Horizontal direction samples and vertical direction samples were cut out in situ. (c) Samples were cut into a cylindrical shape in the site. (d) Samples were wrapped in plastic wrap to ensure that the water content is not lost and then send back to the lab.

\section{Results}

3.1. The Failure Process of Loess. It can be seen from Figure 4 the relationship between fracture development and $\sigma_{t}-h$ (tensile stress-penetration depth) of a sample. Tensile stress has approximately linear growth with penetration depth (from point A to point B) in the initial stage; in this stage, the soil particles nearby loading columns are compacted and can be regarded as elastic deformation. And then, tensile stress has relative stability with the penetration depth increasing (from point $\mathrm{B}$ to point $\mathrm{C}$ ), and the reason may be that the soil nearby the top and bottom of load columns occurred in the shear yield, causing the wedge bodies to have gradually taken shape, and they are the key to generate tensile stress in the process of closing to each other. After point $\mathrm{C}$, the sample is the major bearing tensile stress until it reaches tensile strength (point D). In that process, the tiny vertical fractures can be found from the surface of the sample when the tensile stress almost reaches tensile strength (point $\mathrm{D}$ ), and the tension yield point also occurs in point $D$. After point $D$, the fractures spread quickly from top and bottom to the central. The curve from point $\mathrm{D}$ to point $\mathrm{E}$ is a shakedown process and the tensile fractures are from up to down of the sample, marking the tensile stress dissipating and showing that the tension failure of loess is instantaneous by the UP test. In addition, the tensile stress at point $\mathrm{E}$ is redistributed. The curve of $\sigma_{t}-h$ presents the convex type decreasing (point $\mathrm{E}$ to $\mathrm{F}$ ) and the concave type decreasing (point $F$ to $G$ ). From point $E$ to $G$, the splitting force is a major bearing by the residual tensile stress. Finally, the tensile energy contained in the sample is nearly exhausted, and the sample completely failed into two or three petals like Figure 4(i). After the sample destruction (Figure 5(a)), the wedge splitting body and the splitting angle $(\alpha)$ can be shown clearly in Figure 5(b). The splitting angle $(\alpha)$ and the internal friction angle $(\varphi)$ together determine the coefficient $K$ (equation (2)), and $K$ is an important parameter used to calculate the tensile strength by the UP test. The internal friction angle $(\varphi)$ can be measured by the shear test in the lab; however, there is no direct method to determine the splitting angle $(\alpha)$ at present. Therefore, it has great significance to study the split angle $(\alpha)$.

3.2. The Discussion of Split Angle. Based on the mechanical mechanism analysis of the UP test $[4,9]$, an indirect method can be used to estimate the value of $\alpha$, and the equation can be obtained as

$$
\frac{q_{u} \pi\left[\tan (2 \alpha+\varphi) R H-r^{2}\right]}{P_{\max }}=\frac{2 R H \sin ^{2} \alpha}{r^{2}(1-\sin \varphi) \cos (2 \alpha+\varphi)}+\frac{2 \sin \varphi}{(1-\sin \varphi)} .
$$




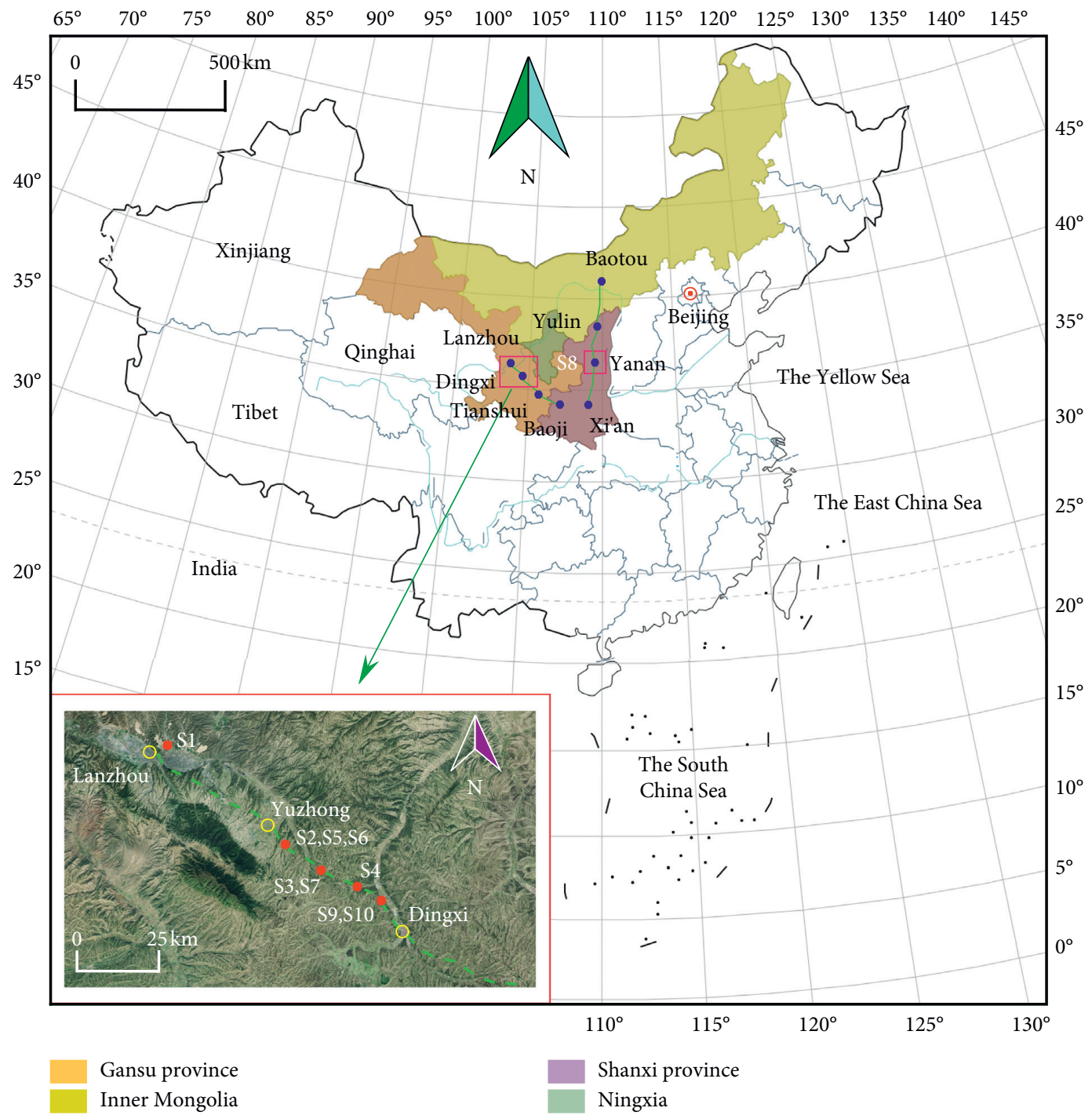

Figure 2: Locations of samples.

TABLE 1: The state of loess in situ.

\begin{tabular}{|c|c|c|c|c|c|}
\hline Sample location & $\begin{array}{l}\text { Section } \\
\text { mileage }\end{array}$ & $\begin{array}{l}\text { Burial depth } \\
(\mathrm{m})\end{array}$ & $\begin{array}{c}\text { Geographic position } \\
\text { (city) }\end{array}$ & $\begin{array}{c}\text { Age of } \\
\text { deposition }\end{array}$ & Apparent properties \\
\hline Artificial slope & Slope foot & 20 & Lanzhou & Q3 & \multirow{2}{*}{ Dry, friability } \\
\hline Wangjiagou tunnel & DK983+898 & 70 & Lanzhou & Q3 & \\
\hline Beiershilipu tunnel & DK953 + 285 & 25 & Dingxi & Q3 & \multirow{3}{*}{$\begin{array}{c}\text { Wet, soft, proteiform, and joint layers } \\
\text { obviously }\end{array}$} \\
\hline Weijiazui tunnel & DK957+ 588 & 30 & Dingxi & Q3 & \\
\hline Xujiachuan tunnel & DK964 + 547 & 150 & Dingxi & Q2 & \\
\hline $\begin{array}{l}\text { Xinbaotashan } \\
\text { tunnel }\end{array}$ & DK502+655 & 100 & Yanan & Q2 & Hard, integrity, dry and strong structure \\
\hline
\end{tabular}

The value of $\alpha$ can be calculated through equation (3). The unconfined compressive strength $\left(q_{u}\right)$, the internal friction angle $(\varphi)$, and the loading force of axial $\left(P_{\max }\right)$ are directly measured, and then, the value of $K$ can be calculated by the difference method. The results of the remolded loess and the undisturbed loess are listed in Tables 3 and 4, respectively.
From Tables 3 and 4, the mean value of the split angle $\alpha$ is $16.67^{\circ}$ for remolded loess and $14.65^{\circ}$ for undisturbed loess. The value of $\alpha$ gradually decreased as a power function with the increase of tensile strength and is finally stabilized nearby $12^{\circ}$ (see Figure 6), and the range of the split angle $\alpha$ is from $11.79^{\circ}$ to $22.58^{\circ}$. The mean value of $2 \alpha+\varphi$ is $62.56^{\circ}$ for the remolded loess and $54.80^{\circ}$ for the undisturbed loess, and the 
TABle 2: Physical properties of samples.

\begin{tabular}{|c|c|c|c|c|c|c|c|}
\hline Sample type & Sample position & Code & $W(\%)$ & $\rho_{d}\left(\mathrm{~g} \cdot \mathrm{cm}^{-3}\right)$ & $e$ & $S_{\mathrm{r}}(\%)$ & PI \\
\hline \multirow{16}{*}{ Remolded loess } & \multirow{14}{*}{ Wangjiagou tunnel } & \multirow[t]{4}{*}{ S1 } & 13 & \multirow[t]{4}{*}{1.70} & \multirow[t]{4}{*}{0.61} & 67.59 & \multirow[t]{4}{*}{13.95} \\
\hline & & & 15 & & & 76.60 & \\
\hline & & & 17 & & & 85.61 & \\
\hline & & & 19 & & & 58.93 & \\
\hline & & \multirow[t]{10}{*}{ S2 } & 11 & \multirow[t]{10}{*}{1.70} & \multirow[t]{10}{*}{0.61} & 49.56 & \multirow[t]{10}{*}{15.56} \\
\hline & & & 12 & & & 54.07 & \\
\hline & & & 13 & & & 58.58 & \\
\hline & & & 14 & & & 63.08 & \\
\hline & & & 15 & & & 67.59 & \\
\hline & & & 16 & & & 72.09 & \\
\hline & & & 17 & & & 76.60 & \\
\hline & & & 18 & & & 81.10 & \\
\hline & & & 20 & & & 90.12 & \\
\hline & & & 13 & & & 58.93 & \\
\hline & \multirow{2}{*}{ Beiershilipu tunnel } & \multirow[t]{2}{*}{ S3 } & 15 & \multirow[t]{2}{*}{1.70} & \multirow[t]{2}{*}{0.60} & 68.00 & \multirow[t]{2}{*}{13.51} \\
\hline & & & 17 & & & 77.07 & \\
\hline \multirow{7}{*}{ Undisturbed loess } & Weijiazui tunnel & S4 & 25.64 & 1.55 & 0.75 & 92.39 & 13.12 \\
\hline & Wangjiagou tunnel $(\mathrm{H})$ & S5 & \multirow{2}{*}{23.03} & \multirow{2}{*}{1.65} & \multirow{2}{*}{0.64} & & \multirow{2}{*}{15.56} \\
\hline & Wangjiagou tunnel (V) & S6 & & & & 95.93 & \\
\hline & Beiershilipu tunnel & S7 & 23.02 & 1.66 & 0.64 & 97.35 & 13.51 \\
\hline & Xinbaotashan tunnel & S8 & 19.64 & 1.68 & 0.63 & 85.29 & 15.95 \\
\hline & Xujiachuan tunnel $(\mathrm{H})$ & S9 & \multirow{2}{*}{14.77} & \multirow{2}{*}{1.92} & \multirow{2}{*}{0.40} & \multirow{2}{*}{1.02} & \multirow{2}{*}{17.76} \\
\hline & Xujiachuan tunnel (V) & S10 & & & & & \\
\hline
\end{tabular}

H: horizontal direction; V: vertical direction.

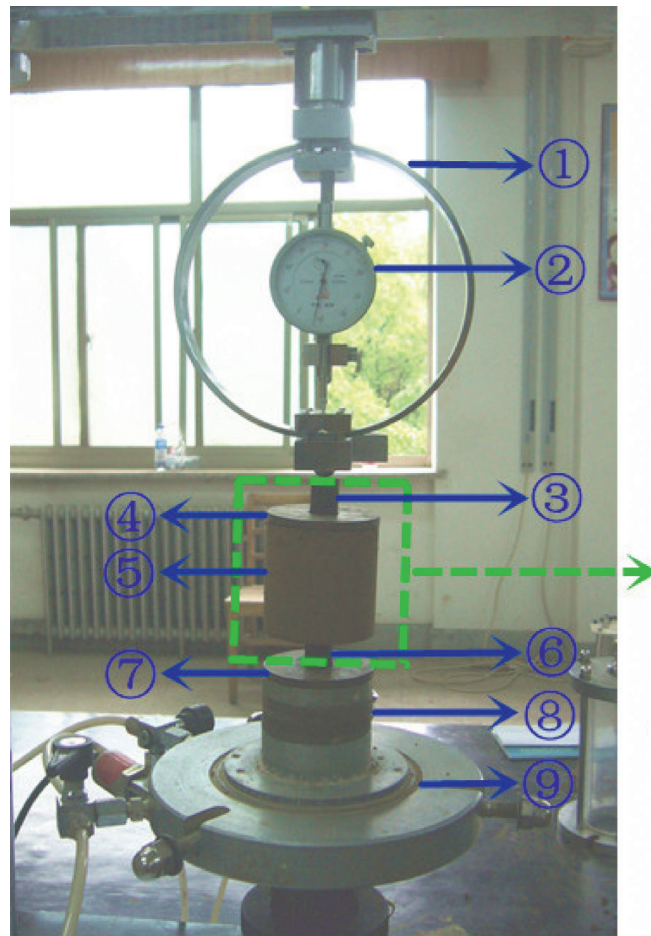
(1) Stress ring
(2) Dial indicator
(3) Top load column
(4) Top centring ring
(5) Sample

(6) Bottom load column

(7) Bottom centring ring

(8) Gasket

(9) Bed plate

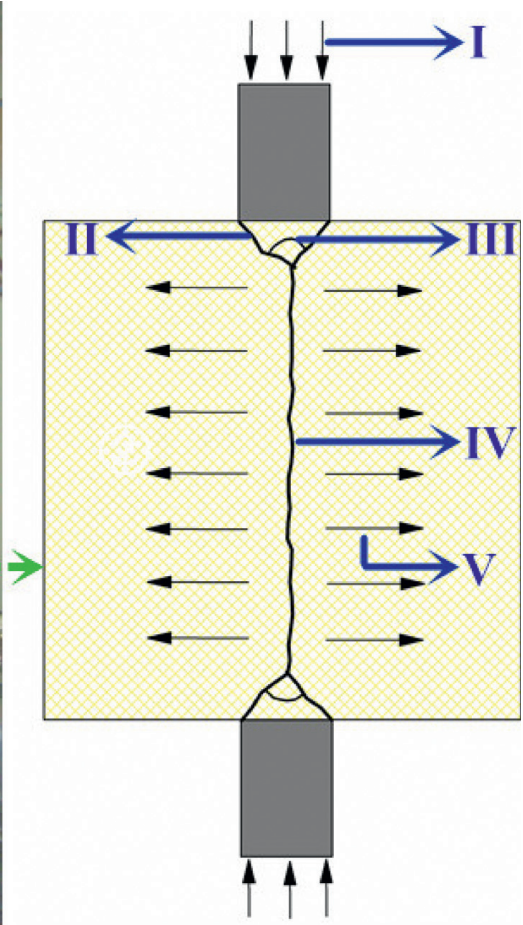

I Load

II Cone body

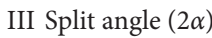

IV Crack surfaces in tension

V Tensile stress

(b)

Figure 3: The apparatus of an unconfined penetration test: (a) actual example; (b) schematic diagram of sample splitting. 


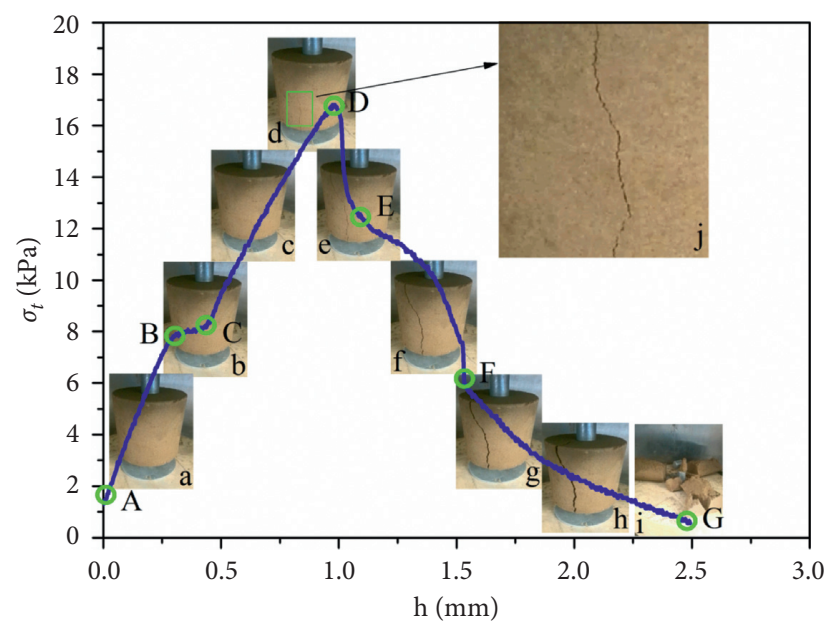

FIgURE 4: The failure process of the sample by the UP test.

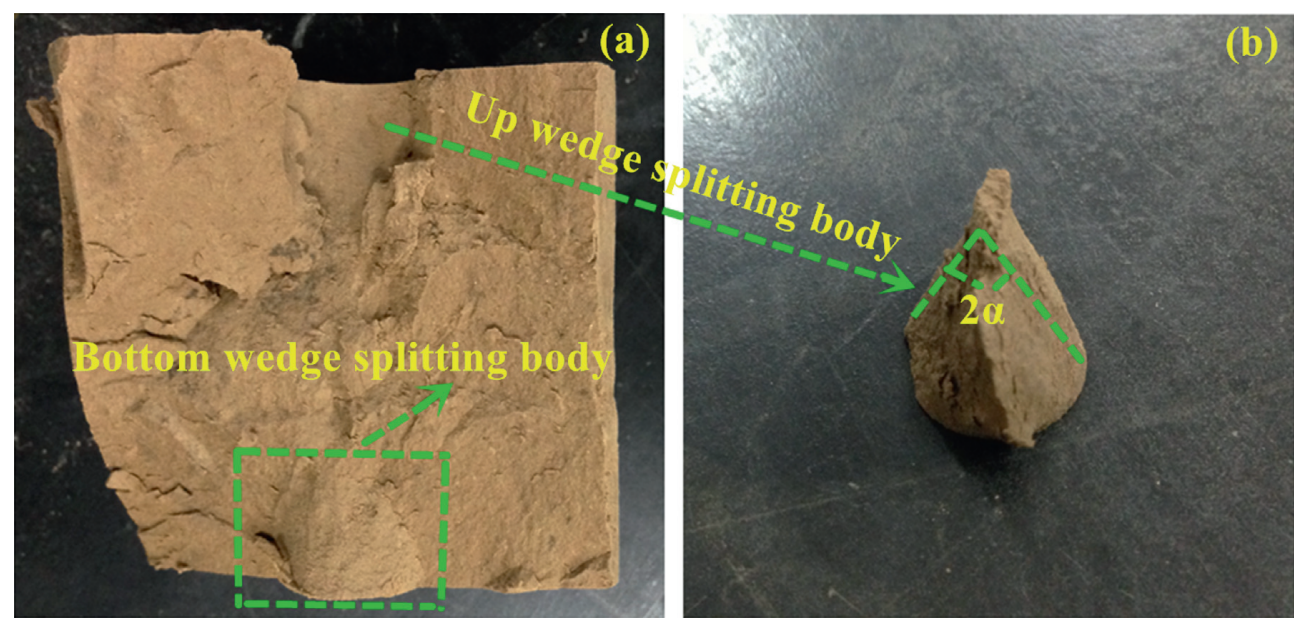

FIGURE 5: The fracture plane of sample and the type of split body by the UP test.

TABLE 3: The statistics value of angle $\alpha$ and modified $K$ (remolded loess).

\begin{tabular}{|c|c|c|c|c|c|c|c|}
\hline Sample number & $q_{u}(\mathrm{kPa})$ & $C(\mathrm{kPa})$ & $P_{\max }(N)$ & $\varphi\left(^{\circ}\right)$ & $\alpha\left(^{\circ}\right)$ & $2 \alpha+\varphi$ & Modified $K$ \\
\hline \multirow{7}{*}{ S1 } & 181.50 & 50.82 & 78.22 & 35.31 & 16.05 & 67.41 & 2.40 \\
\hline & 123.10 & 35.53 & 52.34 & 35.73 & 16.06 & 67.85 & 2.46 \\
\hline & 67.70 & 25.90 & 30.58 & 23.15 & 18.57 & 60.29 & 1.75 \\
\hline & 62.80 & 24.94 & 24.70 & 13.26 & 22.58 & 58.42 & 1.63 \\
\hline & 403.17 & 32.90 & 193.48 & 35.45 & 14.81 & 65.07 & 2.15 \\
\hline & 342.89 & 21.62 & 127.15 & 25.19 & 13.04 & 51.27 & 1.65 \\
\hline & 250.64 & 17.55 & 103.21 & 34.95 & 16.65 & 68.25 & 2.51 \\
\hline \multirow{6}{*}{ S2 } & 195.18 & 16.48 & 96.92 & 28.16 & 16.17 & 60.50 & 1.77 \\
\hline & 150.71 & 15.17 & 89.21 & 33.37 & 13.11 & 59.59 & 1.70 \\
\hline & 126.43 & 10.98 & 64.57 & 32.76 & 14.80 & 62.36 & 1.91 \\
\hline & 89.36 & 7.27 & 42.75 & 33.83 & 15.26 & 64.35 & 2.08 \\
\hline & 77.62 & 6.25 & 36.76 & 34.58 & 15.17 & 64.92 & 2.14 \\
\hline & 57.21 & 4.86 & 28.58 & 18.81 & 17.97 & 54.75 & 1.41 \\
\hline \multirow{3}{*}{ S3 } & 256.00 & 78.56 & 98.80 & 28.86 & 19.17 & 67.20 & 2.38 \\
\hline & 126.40 & 44.20 & 52.34 & 27.94 & 18.49 & 64.92 & 2.14 \\
\hline & 88.60 & 34.67 & 37.05 & 26.07 & 18.84 & 63.75 & 2.03 \\
\hline $\bar{x}$ & 162.46 & 50.86 & 72.29 & 29.21 & 16.67 & 62.56 & 2.01 \\
\hline$s$ & 103.51 & 28.22 & 45.04 & 6.63 & 2.48 & 4.84 & 0.33 \\
\hline$c_{v}$ & 0.64 & 0.55 & 0.62 & 0.23 & 0.15 & 0.08 & 0.17 \\
\hline
\end{tabular}

Note: $\bar{x}$ : arithmetical mean, $\bar{x}=1 / n \sum_{i=1}^{n} x_{i} ; x_{i}$ : measured value; $n$ : sample size; $s$ : standard deviation, $s=\sqrt{1 / n-1 \sum_{i=1}^{n}\left(x_{i}-\bar{x}\right)^{2}} ; c_{v}:$ coefficients of variations, $c_{v}=s / \bar{x}, K^{\prime}:$ modified $K$. 
TABle 4: The statistics value of angle $\alpha$ and modified $K$ (undisturbed loess).

\begin{tabular}{lccccccc}
\hline Sample number & $q_{u}(\mathrm{kPa})$ & $C(\mathrm{kPa})$ & $P_{\max }(N)$ & $\varphi\left(^{\circ}\right)$ & $\alpha\left(^{\circ}\right)$ & $2 \alpha+\varphi$ & Modified $K$ \\
\hline S4 & 81.60 & 37.71 & 41.75 & 12.01 & 18.36 & 48.73 \\
S5 & 96.10 & 50.14 & 52.93 & 20.57 & 17.33 & 55.23 \\
S6 & 148.16 & 49.75 & 77.28 & 21.25 & 16.27 & 53.79 & -1.14 \\
S7 & - & - & 137.79 & - & - & 1.44 \\
S8 & 492.12 & 218.77 & 398.32 & 22.10 & 11.79 & 45.68 & - \\
S9 & 1961.00 & 458.94 & 1093.85 & 40.93 & 11.94 & 64.81 \\
S10 & 2723.24 & 695.97 & 1661.66 & 36.16 & 12.20 & 60.56 \\
$\bar{x}$ & 917.04 & 251.88 & 494.80 & 25.50 & 14.65 & 54.80 & 2.13 \\
S & 1139.81 & 271.52 & 636.66 & 6.26 & 1.73 & 4.12 & 1.77 \\
$c_{v}$ & 1.24 & 1.08 & 1.29 & 0.25 & 0.12 & 0.08 & 0.24 \\
\hline
\end{tabular}

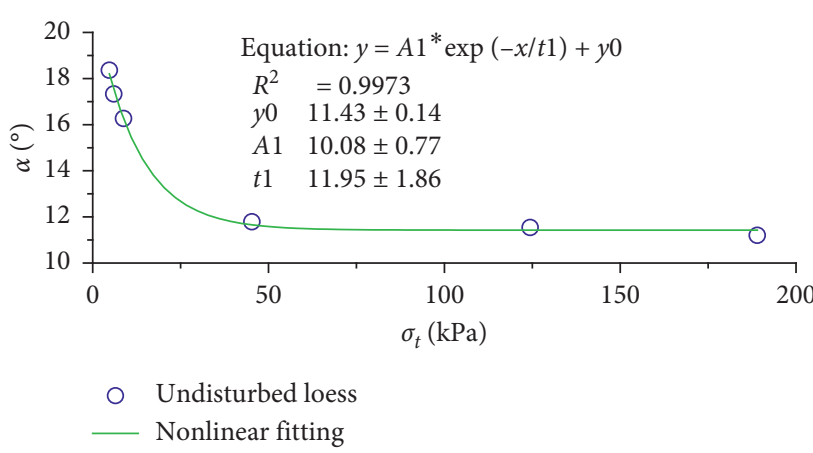

(a)

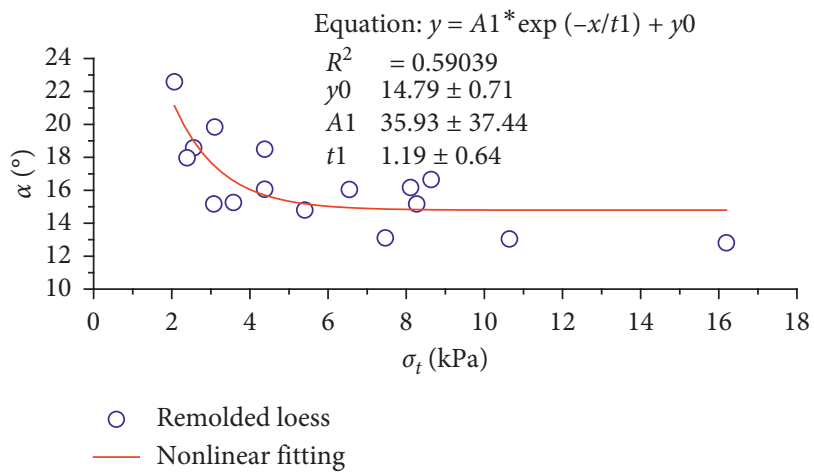

(b)

Figure 6: The relation of tensile stress versus splitting angle.

coefficients of variations are all 0.08 , which are very small. This means that the value of $2 \alpha+\varphi$ is relatively stable, and it can also be elicited that there is a complementary relationship between $\alpha$ and $\varphi$. That relationship can be seen in Figure 7, where the split angle $\alpha$ has approximately linear decrease with the increase of internal friction angle $\varphi$. The value of the modified $K$ is determined by the variation of $2 \alpha+\varphi$, and the results are shown in Tables 3 and 4; for loess samples whose height-diameter ratio is approximately 1 , the modified $K$ should take approximately 2.00 and 1.50 for remolded loess and undisturbed loess, respectively. In addition, a linear relationship exists between unconfined compressive strength, cohesion, and tensile strength after $K$ is modified, and the results are shown in Table 5. The ratio of the unconfined compressive strength to tensile strength of the remolded loess (using $K=2.00$ ) is 1.80 times higher than that of the undisturbed loess (using $K=1.50$ ), and the ratio of the cohesion to the tensile strength of the remolded loess (using $K=2.00$ ) is 2.11 times higher than that of the undisturbed loess (using $K=1.50$ ).

\section{Discrete Element Simulation}

4.1. Mechanism and Failure Criterion of the Discrete Element Method. The discrete element method supposes that the model is composed of discrete particles and only needs to satisfy the force-displacement equilibrium equation and motion balance equation. PFC2D is a discrete element method that originates from molecular dynamics, whose basic units are circular particles and walls which can be used to study the properties and behavior of discontinuous mechanics. Based on the microstructure study, the composition of loess can be regarded as a discrete medium composed of particles and clusters. Therefore, the microfracture process by the UP test can be simulated by PFC2D.

The linear parallel bond model is selected. A parallel bond can be envisioned as a set of elastic springs with constant normal and shear stiffness, uniformly distributed over a circular cross section lying on the contact plane and centered at the contact point (Figure 8(a)). Relative motion at the contact (occurring after the parallel bond has been created) causes a force and a moment to develop within the bond material as a result of the parallel bond stiffness. This force and moment act on the two bonded particles and can be related to maximum normal and shear stresses acting within the bond material at the bond periphery. If either of these maximum stresses exceeds its corresponding bond strength, the parallel bond breaks.

In addition, the reference gap $\left(g_{r}\right)$ defines the contact activity distance between the two particles. Contact activity is determined based on a comparison or tension with the current contact gap $\left(g_{c}\right)$ as follows: if $g_{c}<g_{r}$, the contact is 


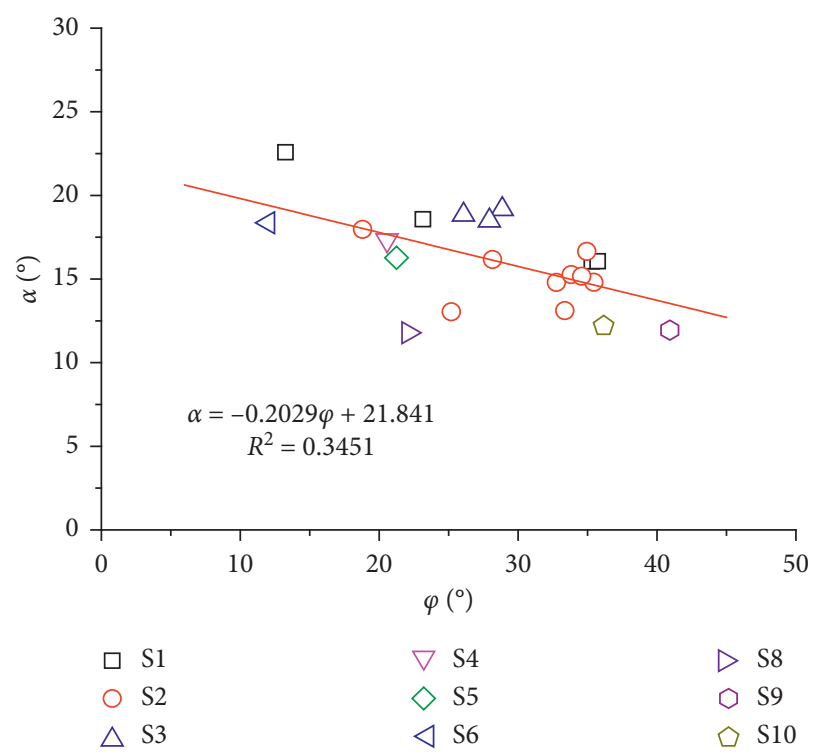

Figure 7: The relation between internal friction angle and splitting angle.

TABle 5: Ratio among the mechanical parameters.

\begin{tabular}{lcccc}
\hline Mechanical parameters & $q_{u-r} / \sigma_{t-r}$ & $c_{r} / \sigma_{t-r}$ & $q_{u-u} / \sigma_{t-r}$ & $c_{u} / \sigma_{t-u}$ \\
\hline Ratio & 26.87 & 8.01 & 14.93 & 3.80 \\
Correlation index $\left(R^{2}\right)$ & 0.9412 & 0.8037 & 0.9921 & 0.9890
\end{tabular}

active; otherwise, the contact is inactive, and fractures are generated. The normal stress $\sigma_{0}^{\prime}\left(\sigma_{0}^{\prime}<0\right.$ is tension $\left.\left(\sigma_{0}^{\prime}\right)\right)$ and shear stress $\tau_{0}^{\prime}$ at the parallel bond periphery are updated as

$$
\begin{aligned}
& \sigma_{0}^{\prime}=\frac{F_{n}}{A_{0}}+\beta_{0} \frac{\left\|M_{b}\right\| R_{0}}{I_{0}}, \\
& \tau_{0}^{\prime}=\frac{\left\|F_{s}\right\|}{A_{0}},
\end{aligned}
$$

where $F_{n}$ is the parallel bond normal force $(\mathrm{N}), A_{0}$ is the average area of two contact particles $\left(\mathrm{mm}^{2}\right), \beta_{0}$ is the moment contribution factor which is a user-defined property between 0.0 and 1.0 (default is 1.0), $M_{b}$ is the parallel bond bending moment $(\mathrm{N} \cdot \mathrm{mm}), I_{0}$ is the parallel bond inertia moment $\left(\mathrm{mm}^{4}\right)$, and $F_{s}$ is the parallel bond shear force $(\mathrm{N})$.
It is satisfied with the tensile-shear coupling strength failure criterion shown in Figure 8(b). These values are checked against the tensile strength $\sigma_{0}^{\prime}$ and shear strength $\sigma_{0}^{\prime}$, and the bond state is updated if the corresponding limit is exceeded:

$$
\begin{aligned}
\left|\sigma_{t}^{\prime}\right| & \leq\left|\sigma_{t}\right| \longrightarrow \text { fail in tensilon, } \\
\tau_{0}^{\prime} & \leq \tau_{0} \longrightarrow \text { fail in shear, } \\
\tau_{0} & =c_{0}-\sigma_{0} \tan \varphi_{0},
\end{aligned}
$$

where $c_{0}$ is the microcohesion and $\varphi_{0}$ is the microinternal friction angle.

4.2. The Formula of Tensile Strength in the Two-Dimensional Model by the UP Test. The UP test is actually the problem of three-dimensional, the calculation formula of the tensile strength (equation (1)) does not suit the two-dimensional model, and building a two-dimensional model in this research can improve the efficiency of calculation.

The formula of the tensile strength can be deduced from equation (3) and described as

$$
\frac{P}{\pi r^{2}}=\sigma_{t}\left[\frac{R H \sin \alpha}{r^{2} \cos (2 \alpha+\varphi) \cos (\alpha+\varphi)}+\frac{R H \sin (\alpha+\varphi)}{r^{2} \cos (\alpha+\varphi)}+\frac{\sin \varphi}{\sin \alpha \cos (\alpha+\varphi)}-\frac{\sin (\alpha+\varphi) \cos \alpha}{\cos (\alpha+\varphi) \sin \alpha}\right] .
$$

It can be further simple as

$$
\frac{P}{\pi r^{2}}=\sigma_{t}\left(\frac{R H \tan (2 \alpha+\varphi)}{r^{2}}-1\right) \text {. }
$$

Under the two-dimension condition, the loading column is a uniform wiring load; therefore, equation (6) can be described as

$$
\frac{P}{2 \mathrm{r}}=\sigma_{t}\left(\frac{R H \tan (2 \alpha+\varphi)}{r^{2}}-1\right) .
$$

And then, the tensile strength formula of the UP test under the two-dimension condition can be described as

$$
\sigma_{t}=\frac{0.5 P}{R H \tan (2 \alpha+\varphi) / r-r} .
$$




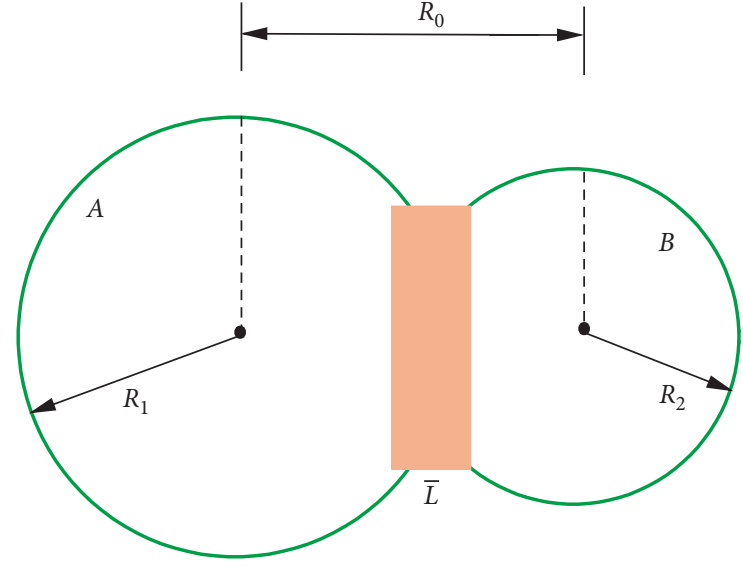

(a)

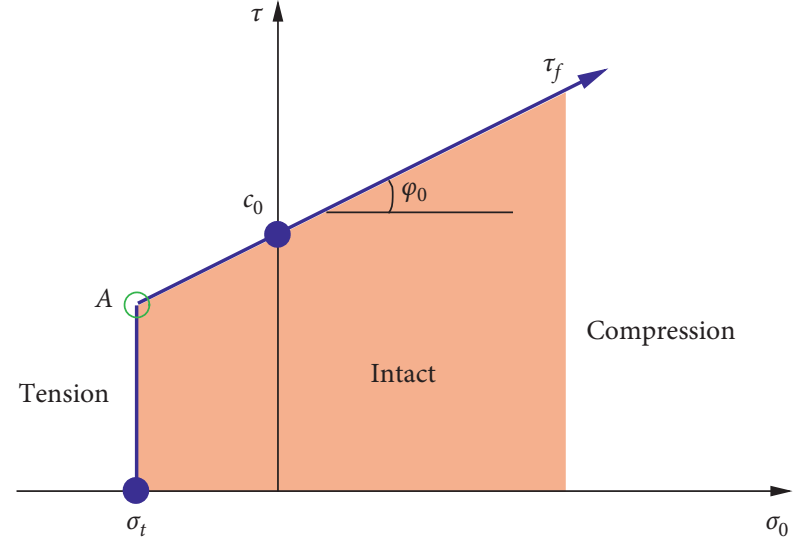

(b)

Figure 8: The bond contact between ball-ball and failure criterion: (a) parallel bond contact; (b) the tensile-shear coupling strength failure criterion.

4.3. Model Build and Parameter Set. In order to study the microfracture process and particle movement law by the UP test, the undisturbed loess taken from the Wangiiagou tunnel is regarded as the simulation object. The sizes of the model sample, loading plates, and loading rate are the same as the UP test in the lab. The loess particles are simulated by balls on account of the fact that the clusters or particles of actual loess are near-spherical; the loading plates are simulated by rigid walls. In order to accord with the actual situation of loess, the numerical model is built based on the actual particle size distribution. The actual grain size of loess was measured by laser method, and the result that can be seen is that the maximum particle size is $120 \mu \mathrm{m}$, and the minimum particle size is $0.76 \mu \mathrm{m}$. If the model was built according to the actual particle size, it will generate too many particles, which will drawback the computational efficiency. Therefore, in order to improve computing efficiency, the model particle sizes are magnified by 20 times compared with the actual loess particle sizes. Finally, the model sample is built up as shown in Figure 9 and generates a total of 7174 balls. The friction strength is simulated by ball contacts, the cohesive strength is simulated by the linear parallel bond contacts, and the contacts between balls and walls are taken linear bond. The grain size of the model sample can be obtained by a measured cycle, and the grain size after the scale-down is similar to that of the actual loess (Figure 10(a)). In order to avoid the initial instantaneous load excessive, the loading rate increases step by step at the initial stage till it increases to $0.1 \mathrm{~mm} / \mathrm{min}$, and the process of the loading rate is shown in Figure 10(b). In addition, the loading halt condition is set as follows: the residual tensile strength is 0.3 times the peak tensile strength. The microparameters which can reflect the strength characteristics of loess are determined by the trial and error method (Figure 11). The particle properties and parallel bond properties are shown in Tables 6 and 7, respectively.

\subsection{Results and Analysis}

4.4.1. Particle Movement and Force Evolution. The development of particle displacement and contact force is shown in Figure 12. At the initial loading stage (before the penetration depth reaches $0.2 \mathrm{~mm}$ ), the particles near the loading plates are gradually compacted. The contacts mainly generated the vertical pressure near the loading plates, and with the tension outward in the vertical direction, the tensile stress is generated. When the penetration depth is from $0.2 \mathrm{~mm}$ to $0.8 \mathrm{~mm}$, the particles near the loading plates are gradually compressed and moved from the top and bottom to the center of the sample. The maximum tensile stress appeared at the axis of the sample; at the same time, the force near the loading plates is gradually presented as a cone shape, which shows that the potential shear yield surface may be the conical surface. In addition, the tension fractures firstly appeared in the middle of the sample, indicating that the sample reaches tensile yield gradually. When the penetration depth is from $0.8 \mathrm{~mm}$ to $1.2 \mathrm{~mm}$, the fractures are spread from the middle of the sample to the top and bottom quickly. When the penetration depth is from $1.2 \mathrm{~mm}$ to $1.4 \mathrm{~mm}$, the force near the axis is fading away and the fractures are increasing, indicating that the contacts are broken and the sample failed in tension. In addition, the force near the loading plates is also fading away with fractures increasing, which presents the fact that the contacts nearby the potential yield surfaces are yielded by shear strength, and the wedge bodies are completely formed. Finally, the sample is destroyed completely (penetration depth at $1.8 \mathrm{~mm}$ ), where the wedge body is presented as coneshaped and the split angle $(\alpha)$ is approximately $15^{\circ}$ just like the actual test in the lab.

4.4.2. Fracture Evolution. The fracture development of the model sample is shown in Figure 13. The sample has no fracture generation at the initial loading stage until the penetration depth reaches $0.6 \mathrm{~mm}$ (point $\mathrm{A}$ ), where the tensile stress (point D) is approximately $70 \%$ of the tensile strength (point E). After point D, the fractures begin to appear and most fractures are generated after the tensile strength (point E), accounting for $2 / 3$ of the total fractures. 

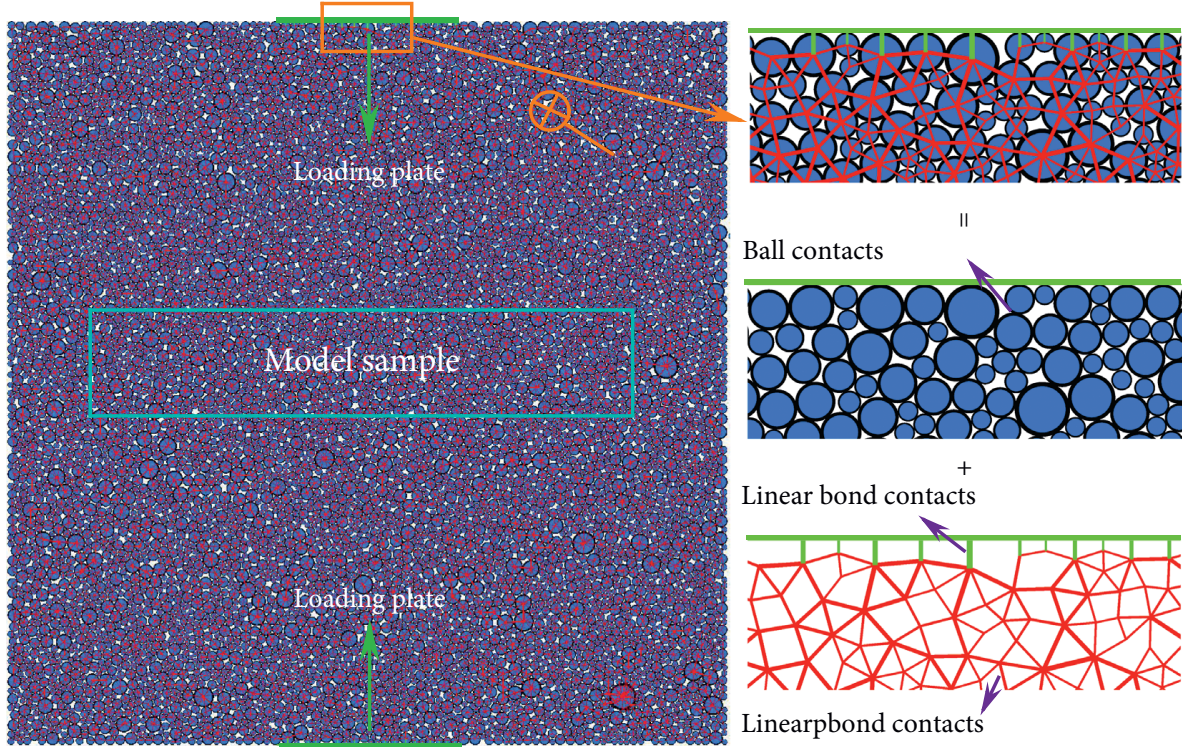

Linear bond contacts

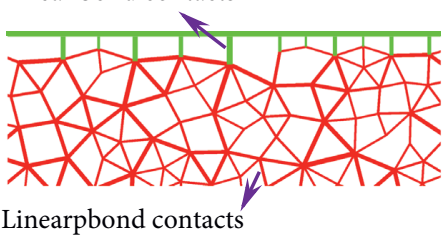

Figure 9: The bond contacts between ball-ball and ball-wall.

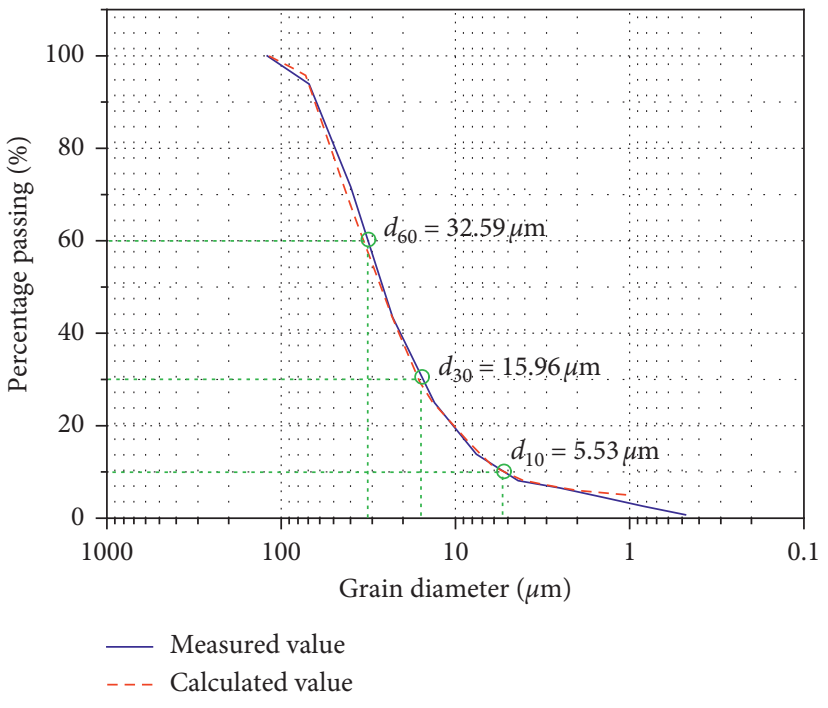

(a)

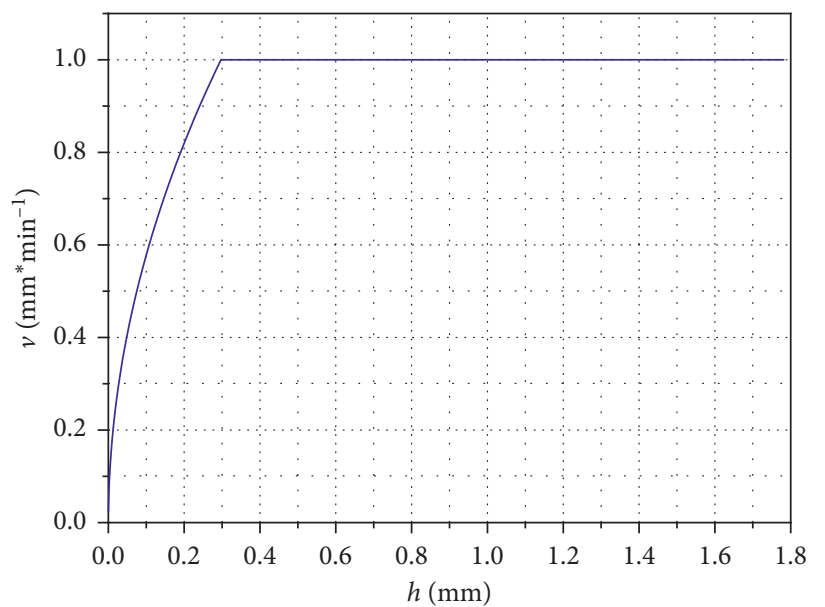

(b)

FIGURE 10: The grain size and load rate (a) the actual grain sizes of loess versus the grain size of the model; (b) load rate versus the penetration depth.

In addition, both tensile fractures and shear fractures are generated and appeared almost at the same time (penetration depth is $0.6 \mathrm{~mm}$, point A) as shown in Figure 14. After point $A$, the number of tensile fractures is higher than shear fractures under the same penetration depth. The shear fractures are gradually stabilized (point C); however, the tensile fractures keep increasing with the penetration depth increasing (points A-D-E), and the tensile fractures are approximately 3 times higher than the shear fractures when the sample is completely destroyed. It can be seen that the failure of the sample is under the tensile-shear coupling condition by the UP test, and the tensile strength plays a major role.

\section{Discussions}

The unconfined compressive strength $\left(q_{u}\right)$, cohesion $(c)$, and the maximum axial load $\left(P_{\max }\right)$ of vertical direction are higher than those of horizontal direction found in Table 4, which indicates that the strength of loess is anisotropic. Loess anisotropy also has an important influence on engineering stability; for example, the slope stability depends mainly on the shear strength of the potential slip surface; however, the shear strength along the potential slip surface is variable and unfixed because of the anisotropy. In this research, the anisotropy of loess is not the point, and it will be studied in the next step. 


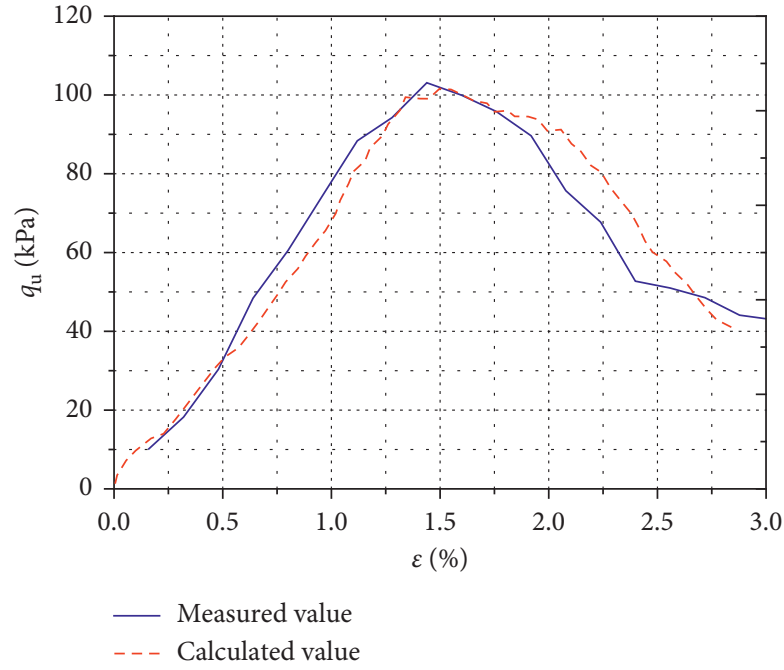

(a)

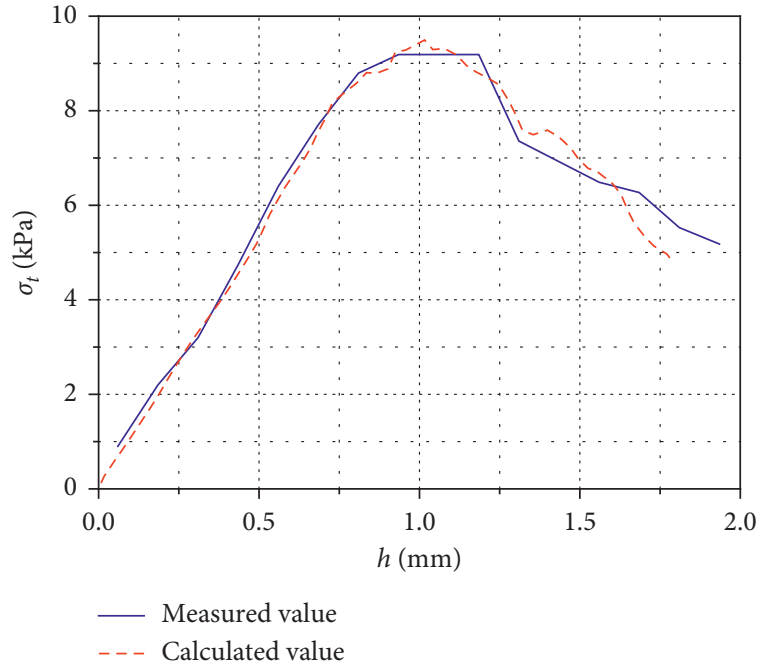

(b)

FIGURE 11: The measured and calculated value of undisturbed loess in Wangjiagou tunnel (a) unconfined compressive strength; (b) tensile strength.

TABle 6: Microparameters of particles.

\begin{tabular}{cccccccc}
\hline Kn & $\mathrm{ks}$ & $\mu$ & $\rho_{s}$ & $n$ & $\mathrm{dp}$ & $\mathrm{r}-\mathrm{max}$ & $\mathrm{r}-\mathrm{min}$ \\
\hline $3 e 6$ & $3 e 6$ & 0.1 & 2600 & 0.1 & 0.7 & 2.4 & 0.01 \\
\hline
\end{tabular}

Note. $\mathrm{kn}$ is the normal stiffness $(\mathrm{N} / \mathrm{m}) ; \mathrm{ks}$ is the shear stiffness $(\mathrm{N} / \mathrm{m}) ; \mu$ is the friction coefficient; $\rho_{s}$ is the density of particles $\left(\mathrm{kg} / \mathrm{m}^{3}\right) ; n$ is the porosity of the model sample; $\mathrm{dp}$ is the damp; $\mathrm{r}$-max is the maximum diameter of particles $(\mathrm{mm}) ; \mathrm{r}$-min is the minimum diameter of particles (mm).

TABLE 7: Microparameters of parallel bond contacts.

\begin{tabular}{lccccccc}
\hline pb_emod & pb_kratio & pb_ten & pb_coh & pb_fa & pb_rmul & pb_ $\mu$ & r_gap \\
\hline $5 e 6$ & 1.0 & $3.5 e 4$ & $3.5 e 4$ & 30 & 0.8 & 0.1 & $5 e-4$ \\
\hline
\end{tabular}

Note. Pb_emod is the effective modulus; pb_kratio is the normal-to-shear stiffness ratio; pb_ten is the tensile strength $(\mathrm{Pa})$; pb_coh is the cohesion $(\mathrm{Pa})$; $\mathrm{pb} \_\mathrm{fa}$ is the friction angle $\left(^{\circ}\right)$; $\mathrm{pb} \_$rmul is the bond radius multiplier; $\mathrm{pb} \_\mu$ is the friction coefficient of parallel bond; $\mathrm{r}$ gap is the reference gap.

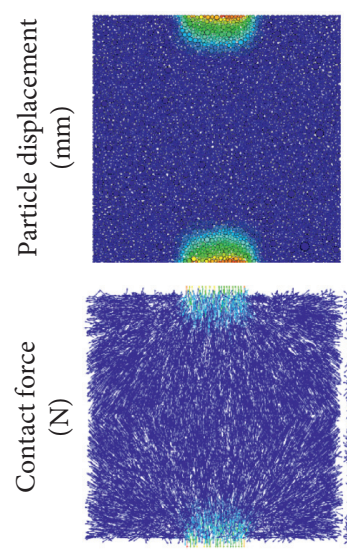

(a)
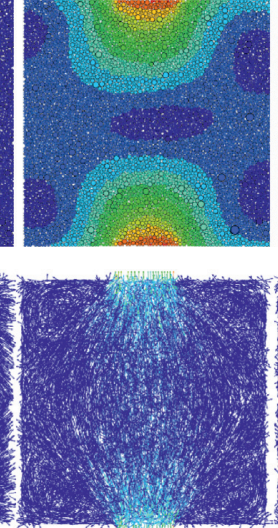

(b)
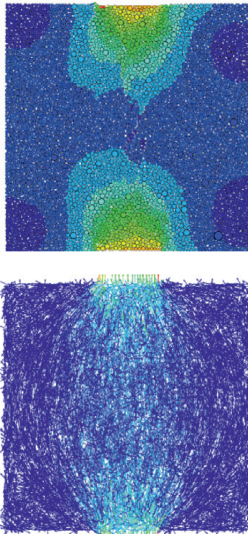

(c)
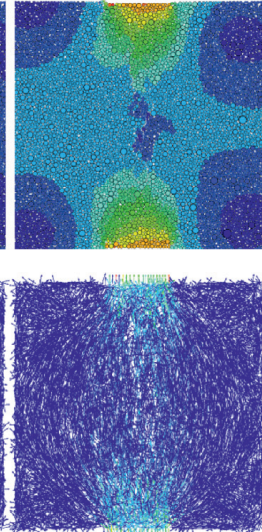

(d)
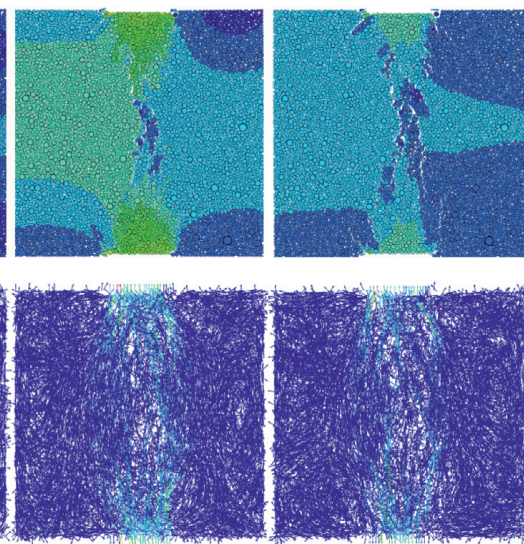

(e)

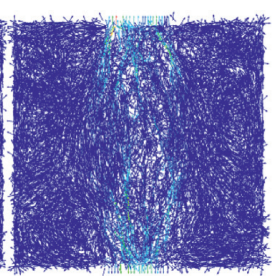

(f)

FIGURE 12: The law of particle displacement and contact force with the penetration depth (note: $h$ is the penetration depth). (a) $h=0.2 \mathrm{~mm}$. (b) $h=0.4 \mathrm{~mm}$. (c) $h=0.8 \mathrm{~mm}$. (d) $h=1.2 \mathrm{~mm}$. (e) $h=1.4 \mathrm{~mm}$. (f) $h=1.8 \mathrm{~mm}$. 


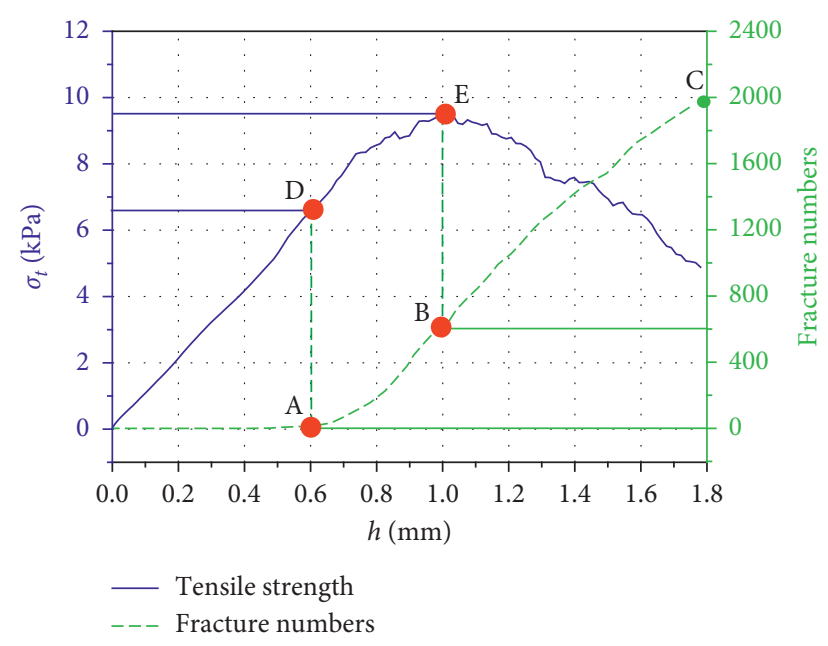

FIgURE 13: The stress-penetration depth versus fractures.

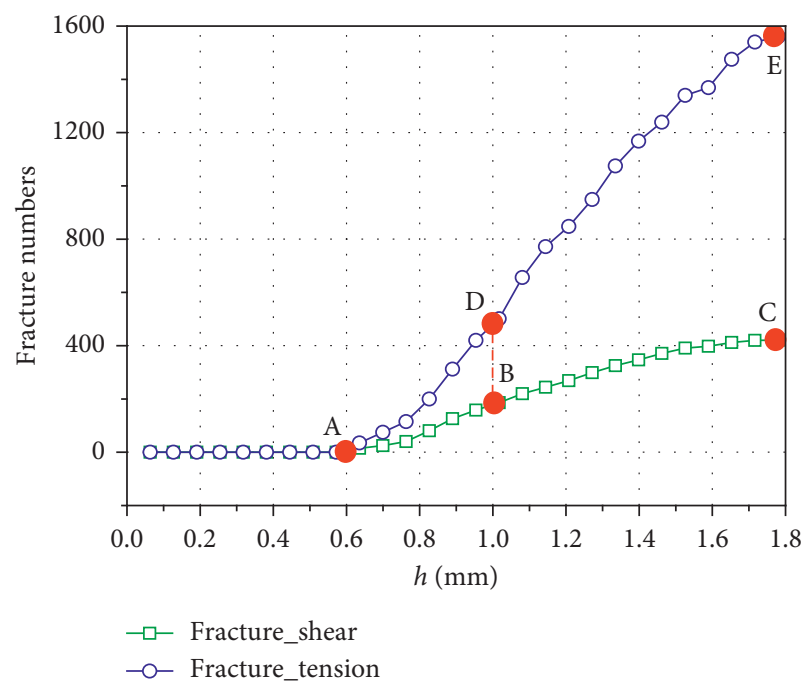

Figure 14: The penetration depth versus tension fractures and shear fractures.

Combining particle displacement law, force evolution law, and fractures development, the mechanical process of the testing tensile strength of loess by the UP test can be described as follows: the tensile fractures firstly appeared in the center of the sample and then spread to the top and bottom; after the peak tensile strength, the number of fractures grows rapidly and the wedge bodies are formed; finally, with the penetration depth continuing increasing, the tensile stress decreases sharply and the sample completely fails. In the process of sample failure by the UP test, both tensile strength and shear strength contribute to resisting the axial force. The shear strength is composed of cohesion strength and friction strength. The tensile strength and the cohesion strength are caused by the bond contacts among particles; however, the friction strength is caused by the relative movement of particles. Therefore, the UP test is a complex mechanical process with tensile strength providing major resistance; meanwhile, local shear strength plays an auxiliary role.

\section{Conclusions}

The UP tests, triaxial shear tests, and unconfined compressive strength tests are conducted in the lab to study the applicability of the tensile strength formula for loess. In addition, the cracking process of the sample is simulated by the discrete element method. Finally, the conclusions can be conducted as follows:

(1) The split angle $(\alpha)$ of remolded loess and undisturbed loess is $16.67^{\circ}$ and $14.65^{\circ}$, respectively; and it decreases with the tensile strength increasing; moreover, it has the complementary relationship between split angle $(\alpha)$ and internal friction angle $(\varphi)$, which means that the split angle has an approximately linear increase with the internal friction angle decreasing

(2) The modified coefficient $K$ is recommended to be 2.00 for remolded loess and 1.50 for undisturbed loess

(3) The fractures are not generated until the tensile stress exceeds $70 \%$ of the tensile strength, and it is spread from the center to the top and bottom of the sample

(4) The axial force is a major bearing by the tensile strength, and shear strength plays an auxiliary role

\section{Data Availability}

The data used to support the findings of this study are included within the article.

\section{Conflicts of Interest}

The authors declare that they have no conflicts of interest.

\section{Acknowledgments}

The authors appreciate the support of the National Science Foundation of China (51968041), the Science and Technology Department of Henan Province, China (212102310965 and 212102310933), and Natural Science Foundation for Youth of Henan Province (212300410106).

\section{References}

[1] P. Sun, J.-B. Peng, L.-W. Chen, Y.-P. Yin, and S.-R. Wu, "Weak tensile characteristics of loess in China-an important reason for ground fissures," Engineering Geology, vol. 108, no. 1-2, pp. 153-159, 2009.

[2] G. Leonard and J. Narain, "Flexibility of clay and cracking of earth dams," Journal of the Soil Mechanics and Foundations Division, ASCE, vol. 89, no. S2, pp. 47-70, 1963.

[3] Y. Zheng, H. Ye, and R. Huang, "Analysis and discussion of failure mechanism and fracture surface of slope under earthquake," Chinese Journal of Rock Mechanics and Engineering, vol. 28, no. 8, pp. 1714-1723, 2009.

[4] H. Fang and J. Daniels, Introductory Geotechnical Engineering-An Environmental Perspective, Taylor \& Francis Group, Milton Park, UK, 2006.

[5] T.-H. Kim, T.-H. Kim, and G.-C. Kang, "Factors influencing crack-induced tensile strength of compacted soil," Journal of 
Materials in Civil Engineering, vol. 24, no. 3, pp. 315-320, 2012.

[6] R. Li, J. Liu, R. Yan, W. Zheng, and S. Shao, "Characteristics of structural loess strength and preliminary framework for joint strength formula," Water Science and Engineering, vol. 7, no. 3, pp. 319-330, 2014.

[7] X. Wu, Q. Liang, F. Niu, C. Li, and L. Wang, "Anisotropy of intact loess of Wangjiagou tunnel along Baoji-Lanzhou passenger dedicated line," Rock and Soil Mechanics, vol. 37, no. 8, pp. 2373-2382, 2016.

[8] F. Ma, J. Yang, and X. Bai, "Water sensitivity and microstructure of compacted loess," Transportation Geotechnics, vol. 11, pp. 41-56, 2017.

[9] Q. Liang, X. Wu, C. Li, and L. Wang, "Mechanical analysis using the unconfined penetration test on the tensile strength of Q3 loess around Lanzhou City, China," Engineering Geology, vol. 183, pp. 324-329, 2014.

[10] Y. Li, "A review of shear and tensile strengths of the malan loess in China," Engineering Geology, vol. 236, pp. 4-10, 2018.

[11] X. Wu, F. Niu, Q. Liang, and G. Li, "Study on tensile strength and tensile-shear coupling mechanism of loess around Lanzhou and yanan city in China by unconfined penetration test," KSCE Journal of Civil Engineering, vol. 23, no. 15, pp. 1-12, 2019.

[12] S.-Q. Yang and Y.-H. Huang, "Particle flow study on strength and meso-mechanism of Brazilian splitting test for jointed rock mass," Acta Mechanica Sinica, vol. 30, no. 4, pp. 547-558, 2014.

[13] X. P. Zhang and L. N. Y. Wong, "Cracking processes in rocklike material containing a single flaw under uniaxial compression: a numerical study based on parallel bonded-particle model approach," Rock Mechanics and Rock Engineering, vol. 45, pp. 711-737, 2012.

[14] Q. Zhang, X.-P. Zhang, and S.-Q. Yang, "A numerical study of acoustic emission characteristics of sandstone specimen containing a hole-like flaw under uniaxial compression," Engineering Fracture Mechanics, vol. 242, no. 3, Article ID 107430, 2021.

[15] Y. Ju, H. F. Sun, M. X. Xing, X. F. Wang, and J. T. Zheng, "Numerical analysis of the failure process of soil-rock mixtures through computed tomography and PFC3D models," International Journal of Coal Science \& Technology, vol. 5, no. 2, pp. 126-141, 2018.

[16] M. Jiang, F. Zhang, and H. Hu, "DEM modeling mechanical behavior of unsaturated structural loess under constant stress increment ratio compression tests," International Journal of Geomechanics, vol. 17, no. 4, Article ID 04016108, 2017.

[17] Z. You, M. Zhang, F. Liu, and Y. Ma, "Numerical investigation of the tensile strength of loess using discrete element method," Engineering Fracture Mechanics, vol. 247, Article ID 107610, 2021. 